\title{
APPLICATION OF TUTORING IN A PROJECT AND RESEARCH ACTIVITY UNDER BASIC PROFESSIONAL EDUCATION
}

\author{
Olga BYKANOVA ${ }^{1}$, Irina AVVAKUMOVA ${ }^{2}$, Ravil AKHMADEEV ${ }^{3^{*}}$, Tatiana \\ MOROZOVA ${ }^{4}$, Maxim PROTASOV ${ }^{5}$ \\ ${ }^{1}$ Associate Prof., Plekhanov Russian University of Economics, Russian Federation, \\ bykanova@inbox.ru \\ ${ }^{2}$ Senior Lecturer, Plekhanov Russian University of Economics, Russian Federation, \\ imba52@mail.ru \\ ${ }^{3}$ British Doctor of Philosophy degree (PhD) standard, Associate Prof., Plekhanov Russian \\ University of Economics, Russian Federation, ahm rav@mail.ru \\ ${ }^{4}$ Associate Prof., Plekhanov Russian University of Economics, Russian Federation, \\ isfyrmorozova@gmail.com \\ ${ }^{5} \mathrm{SD}$, Plekhanov Russian University of Economics, Russian Federation, tkoz84@mail.ru \\ ${ }^{*}$ Corresponding Author
}

\begin{abstract}
Providing senior students with a basic professional education in the field of economics and management is most effective when applying a project and research activity, as well as the analysis of modern data and digital technologies methods. At the same time, introducing initial specialized education in the field of economics and managerial orientation, implemented in the "school - higher educational institution" paradigm, does not imply the formation of narrow specialists, but reveals to them actual attractive facets in a particular field, highlighting the competencies of the future profession they have chosen, different aspects of which they encounter daily. In this regard, the most important today is the transition to a more sophisticated "teacher-tutor" level of education, which helps to look at the research problem from a different angle so that the "ideal" images in senior students' minds could lead to the formulation of vital ideas which will transform the reality of the world. As a result of the studies carried out on the application of the project and research activity in the "school - university - employer" link, the following important features have been identified. Thus, $70 \%$ of future applicants, who realize their creative potential participating in research competitions and various contests, have the goal of entering universities of an economic and management profile. Consequently, such activities of enrollees result in the desire to change the situation for the better, including the situation in the country. Therefore, expanding the horizons of knowledge and skills at the "teacher - tutor" level for adolescents, allows them to more competently relate to finances in their family, adapt the knowledge gained to their actions and critically assess the consequences of their decisions.
\end{abstract}

Keywords: education, digital technologies, professional competencies, project activities, government funding.

\section{INTRODUCTION}

Each generation, while defining its own outlook and ways of transforming the surrounding world, builds its own strategy in accordance with modern technological potential. However, the psychological aspects of the personality formation stages, despite the changing background, are quite clearly defined (Arco-Tirado, 2003, p. 585). At the same time, the impact that educational structures such as the family, society, and school 
make on the self-determination of a teenager as a person and a citizen, deserves special attention. By selfdetermination of the individual we mean the independent choice of one's life goals and ways of achieving them, considering moral and spiritual values, as well as internal attitudes for analyzing actions and their consequences.

Moreover, one of the most important aspects that characterizes the personality is professional selfdetermination, which allows a person to realize his "internal" interests in the "external" world (HerzogPunzenberger, 2020). Obviously, choosing a future professional activity, and, therefore, positioning himself in the surrounding environment, determines the strategy of the young person's life which he implements by interacting with all possible sources of information of a theoretical and practical nature. Such information is provided by educational institutions of a vocational and higher level, cultural and educational centers, as well as production processes and businesses represented by future employers.

\section{THEORETICAL BACKGROUND}

\subsection{Literature Review}

Initial professional education in the field of economics and management, provided to high school students, is most effective when using a project and research activity (Ternovykh, 2020) as well as analyzing modern data and applying digital technologies. A feature of this approach, according to Voronova (2019), underlies the influence of the following aspects. Despite the insufficient amount of theoretical knowledge in the field of mathematics and economics, the use of computer technologies allows senior students to hide the computing apparatus and obtain conclusions that may or may not be consistent with the surrounding reality. Therefore, it is necessary to carefully select research topics that may arouse some interest in a person.

Firstly, we should agree on the concepts of "project" and "research" in accordance with the goal set, which is the formation of such a personality aspect as professional self-determination (Czepczyński, 2020). In the research Bray (2015) a "project" is characterized, among other things, as a representation of the ideal future, which may not yet exist, but it should be. On the other hand, according to the study (Korableva, 2019), the concept of "research" is reflected by the search for the unknown ideal future (Shenoy, 2020). Consequently, for future specialists who only try to find their path in life, also in a professional sense, just the symbiosis of project and research activities can be regarded as an optimal method for studying the world around them, since in this case it is performed simultaneously:

a) on the one hand, a certain "ideal" hypothesis is formulated, which is consistent with the studied phenomenon (process, etc.);

b) on the other hand, the collection and analysis of data available to the researcher allows him to independently compare the real facts with the "ideal" view of modern reality.

\subsection{Data Analysis}

The ideal implementation of the "project" and "research" can be determined by the fact that many young people have a Panglossian view on the surrounding world, without assuming the complexity of often mutually exclusive factors that affect the personality and its place in society. It should also be noted that the following aspects should be considered when conducting the research:

a) age-related psychological characteristics of adolescents, which do not allow them to fully understand and evaluate some problems (Kalacheva, 2019; Petrova, 2019);

b) the relevance of the study to the age group, since it requires a sincere interest to study all the nuances (Gorlanov, 2019);

c) the level of proficiency in theoretical material (mathematical apparatus, economic knowledge, concepts);

d) the level of knowledge of information technology, since it is this resource that allows bypassing complex mathematical calculations in data processing.

It should be mentioned that basic professional education of economic and managerial orientation, implemented in the "school - higher educational institution" link, does not imply the formation of specialists from adolescents, but reveals to them actual interesting facets in a specific area, taking into account the competencies provided to them in the chosen future profession, different aspects of which they encounter every day. In this regard, the most important today is the transition to a more sophisticated application of educational tools at the "teacher-tutor" level, which helps to look at the research problem in such a way that the "ideal" representation in senior students' dreams could generate real ideas for transforming the reality of 
the world. Therefore, mundane daily activities can be transformed for senior students into an educational quest:

a) Involving practical issues such as shopping in a store (where is it more profitable to purchase and why?), future planning of the family budget (why does a future graduate need this and how to properly spend money in the current economic situation under COVID-19?);

b) Containing business issues such as finding a well-paid job (how to choose the right employer), paying taxes (rights without obligations do not exist in the state).

\section{RESULTS AND DISCUSSION}

As a result of the conducted studies in the system of secondary and higher education, taking into account the influence of restrictions on the level of knowledge, we have proposed the following approaches to the development of the "teacher-tutor" method.

\subsection{Analysing the Consumer Basket and Minimum Wage}

Will there be enough food for a teenager? Since the grocery basket constitutes half of the consumer basket in monetary terms, it was decided to analyze it taking into account the age needs of senior students (the growth and formation of the organism continues) on the basis of the approved norms of various substances, as well as gender differences. Moreover, two groups of senior students were involved in this activity. The first group calculated an economical option, i.e. food to support life, but without breaking the standards. While the second group studied a balanced diet with a wide variety of products, but without frills. To collect information on current prices for specific groups of products from the list of the grocery basket, both groups of schoolchildren visited both chain stores and convenience stores (Kevorkova, 2020). The next step was the choice of a method for processing a sufficiently large amount of information, which should have been based on the theoretical foundations of mathematical programming, since the problem of the diet is its classical representation. To sort out an economic problem, it is advisable to formulate its mathematical model and find the solution, on the basis of which we have come up with a method for solving an economic problem. Considering the study as a mathematical model, it is assumed to search for the optimal, i.e. lowest, cost of the diet, where one should adhere to the following instructions:

1) The variables will determine the volumes of food resources $x_{i j} \geq 0$, which will be included in the food basket;

2) Norms of supply of vitamins and minerals will be presented in the form of linear inequalities;

3) The objective function is the cost of the grocery basket, which can be determined by the following formula:

$$
\begin{aligned}
& F\left(x_{i}\right)=\sum_{i=1}^{i=k} c_{i} x_{i} \rightarrow \min \\
& \left\{\begin{array}{l}
a_{11} x_{1}+\cdots+a_{1 k} x_{k} \geq b_{1} \\
\cdots \cdots \cdots \cdots \cdots \cdots \cdots \cdots \cdots \cdots \cdots \cdots \cdots \cdots \cdots \\
a_{n 1} x_{1}+\cdots+a_{n k} x_{k} \geq b_{n}
\end{array}\right.
\end{aligned}
$$

where $c_{i}$ is the cost of the corresponding product;

$a_{i j}$ represents the content of a certain type of vitamin or mineral in the corresponding product.

The technical aspect of solving the problem was ensured using computer technologies, a wide range of which to process large amounts of data is almost unlimited. In this regard, the study of senior pupils' activities resulted in two food schemes for girls and boys (Table 1).

Table 1. The minimum cost of a grocery basket.

\begin{tabular}{|l|l|l|l|l|}
\hline \multirow{2}{*}{ Indicators } & \multicolumn{2}{|l|}{ Boys (15-17 years old) } & \multicolumn{2}{l|}{ Girls (15-17 years old) } \\
\cline { 2 - 5 } & Economy food & Diverse food & Economy food & Diverse food \\
\hline Monthly expenses & 67,5 & 240,0 & 47,5 & 200,0 \\
\hline
\end{tabular}

Taking into account that the minimum wage at the time of the project was USD 312 in Moscow and 
assuming that there were 2 working parents in the family and the child did not work, the participants in preprofessional education were able to formulate the following conclusions:

a) Calculating monthly expenses for a family of 3 people, we received a value of 47.5 to 67.5 US dollars in the form of food expenses, which suggests an economical option that does not provide full body development of adolescents;

b) Gender differences seriously affect the financial side of family budget planning, i.e. the cost of a food basket for males is higher.

\subsection{Credit to take it or not?}

Financial and credit relations can be considered as a foundation of the modern world with financial literacy being a security issue in the context of cybercrime in the economy. One of the topical issues for research studies offered by tutors to high school students relates to a student loan. The desire to independently make important decisions and be responsible for them implies some monetary basis, and, consequently, the ability to manage finances. When calculating the value of regular equal payments on a loan (annuity), it was proposed to use the following formula:

$R=\frac{i *(1+i)^{n}}{(1+i)^{n}-1} * S$

where, assuming that all indicators are reduced to a month as a time base, i.e.

i - interest rate per month;

$\mathrm{R}$ - monthly payment;

$\mathrm{n}$ - the number of payments for the entire period of using a loan of $\mathrm{S}$.

In the process of carrying out an analytical comparison of annuity and differentiated schemes of credit payments, considering the amount of income and the regularity of its replenishment, differentiated payments were determined by the formula changing with the payment number:

$R_{m+1}=\frac{s}{n}-\left(S-\frac{s}{n} * m\right) * i$

where, under the assumption that a month is taken as the time base, i.e.

$\mathrm{i}$ - interest rate per month

$\mathrm{R}$ - monthly payment,

$\mathrm{n}$ - the number of payments for the entire period of using the loan by $\mathrm{S}$ value,

$\mathrm{m}$ - the number of payments already made (starts from 0 ).

The participants of initial professional education of economic and management orientation have compared loans from various banks relying on the bank data on the values of credit rates and the conditions for granting and repaying loans, taking into account the specifics that a project teacher-tutor has offered to choose from. This approach made it possible to select proposals that are the most convenient and expediently adequate to the following requirements and restrictions:

a) The possibility of non-periodic additional payments (if the income is of a contractual irregular nature);

b) The possibility of early repayment or restructuring of the loan (if it is impossible to fulfill obligations to the lender);

c) The possibility to analyze the stability of their own solvency in the medium term.

The research work has resulted in a student's choice of one or another form of lending, grounded in numbers, or a blank refusal of similar banking products.

\subsection{Working as an Individual Entrepreneur. Obligations to the State}

The state apparatus assumes that any citizen has duties in addition to civil rights. One of them is paying taxes. Participants in initial professional education in economics and management, imagining an "ideal" profession, and hence income from their type of activity usually see themselves as entrepreneurs enjoying great opportunities (Golubtsova 2019). However, we should not forget that it is necessary to strictly follow the legislation in terms of tax payment, for which it is necessary to correctly define oneself from the point of view 
of tax legislation. An individual entrepreneur can apply a patent for a type of activity established by the state Zvereva (2020) or apply a simplified taxation system, or until 2021 pay UTII (a limited number of regimes are being considered, namely, preferential ones).

Each regime assumes its own conditions and restrictions and requires accurate calculation of the income and expenditure parts (Lehoux, 2019). Participants in initial professional education of economic and management orientation were offered by the teacher-tutor a type of activity dealing with the provision of services (work performance) on the development of computer programs and databases (software and information products of computer technology), either their adaptation and modification, or the repair of computers and communication equipment (Sharafutdinov, 2019).

In this regard, firstly, they are included in the list for patent taxation (Turishcheva, 2019; Petrov, 2020), and secondly, in view of active digitalization, this type of activity is more understandable (Voronova, 2020). At the same time, a distinctive feature of patent taxation is the fact that the value of a patent (namely, tax) is determined not by actual income, but by potential income. Moreover, the estimated income is calculated with reference to the geographical area.

\section{CONCLUSION}

The productive part of the project and research activity of the school - university - employer paradigm is undoubtedly represented in the ratings of economic universities and job competitions in the financial area. About $70 \%$ of schoolchildren who realize their creative potential in research competitions and various battles come to study at universities of economic and managerial profile.

The result of this work is the desire to change the situation for the better, in the country as well. Expanding the horizons of their knowledge and skills, adolescents begin to relate to finances more competently in their family, adapt the knowledge gained to their actions, and critically accept the consequences of their decisions. The economy is the cornerstone of the state functioning, which affects self-determination of senior students as individuals and citizens. Moreover, it is not an inertial substance, since everyone makes a greater or lesser contribution to changing the decision made. Thus, only using the digital technologies available today in the field of the technical and psychological development, it is possible to evolve a creative character in the younger generation, which will naturally lead to a more progressive change of the country economy as a whole in the future.

\section{REFERENCE LIST}

Arco-Tirado, J. L. and Fernández-Balboa, J. M. (2003) Contextual barriers to school reforms in Spain. International Review of Education, vol. 49(6), p. 585-600.

Bray, M. and Kobakhidze, M.N. (2015) Evolving ecosystems in education: The nature and implications of private supplementary tutoring in Hong Kong. Prospects. vol.45, p. 465-481.

Czepczyński, R. and Kunikowska, J. (2020) Teaching nuclear medicine in the pandemic-a new challenge for the faculty. European Journal of Nuclear Medicine and Molecular Imaging. vol. 47, p. 2075-2077.

Golubtsova, E.V. and Zvereva, A.O. (2019) Development of Tax Attractiveness of Russia's Special Administrative Areas with Fair Tax Competition. Proceedings of the 34th International Business Information Management Association Conference, IBIMA 2019: Education Excellence and Management of Innovations through Sustainable Economic Competitive Advantage Vision 2025, p. 2023- 2028.

Gorlanov, S., Medelyaeva, Z., Malitskaya, V., Chirkova, M. and Kostyukova, E. (2019) Content analysis the term "effectiveness" and the concepts of its quantitative characteristics. Indo American Journal of Pharmaceutical Sciences. vol. 6 (3), p. 5293-5298.

Herzog-Punzenberger, B., Altrichter, H. and Brown, M. (2020) Teachers responding to cultural diversity: case studies on assessment practices, challenges and experiences in secondary schools in Austria, Ireland, Norway and Turkey. Educational Assessment, Evaluation and Accountability. vol. 26 https://doi.org/10.1007/s11092-020-09330-y

Kalacheva, O. N. (2019) A Survey of Modern E.U. Approaches towards Amortization Policies. Proceedings of the 34th International Business Information Management Association Conference, IBIMA 2019: 
Education Excellence and Management of Innovations through Sustainable Economic Competitive Advantage Vision 2025, p. 4515 - 4522.

Kevorkova, Z. A., Zhukova, G. S., Antonova, O., Dolbik-Vorobey, T. A. and Petrov A. M. (2020) Organizational prerequisites for transition to IFRS in the artificial intelligence context. Bulletin of the National Academy of Sciences of the Republic of Kazakhstan. vol. (384), p. $128-136$.

Korableva, O., Durand, T., Kalimullina, O. and Stepanova, I. (2019). Studying user satisfaction with the MOOC platform interfaces using the example of coursera and open education platforms. Paper presented at the ACM International Conference Proceeding Series, p. 26-30. doi:10.1145/3322134.3322139

Lehoux, L., Morozova, T.V., Safonova, E.G., Balashova, A.D. and Protasov, M.V. (2019) Practical Aspects in Calculating of Impairment of Financial Assets According to IFRS 9 "Financial Instruments". Proceedings of the 33rd International Business Information Management Association Conference, IBIMA 2019: Education Excellence and Innovation Management through Vision 2020, p. 6624-6632.

Petrov, A. M. and Sembiyeva, L. M. (2020) Organizational and methodical mechanism of internal audit of settlements in corporate systems. Bulletin of the National Academy of Sciences of the Republic of Kazakhstan. vol.2 (384), p. $119-127$.

Petrova G., Posadneva E. and Morozova T. (2019) Leading the labour market by the law of supply and demand. Sustainable Leadership for Entrepreneurs and Academics. Springer Proceedings in Business and Economics. Springer, p. 263-271.

Sharafutdinov, R., Gerasimov, V., Akhmetshin, E., Karasik, E. and Kalimullina, O. (2019). Inclusive development index in Russia: analysis, methods, possibility of application. Revista Genero \& Direito, vol. 8(4), p. 231-241.

Shenoy, A. and Petersen, K.H. (2020) Peer Tutoring in Preclinical Medical Education: A Review of the Literature. Medical Science Educator. vol. 30, p. 537-544.

Ternovykh, K., Leonova, N., Malitskaya, V., Chirkova, M. and Markova, A. (2020) State and effectiveness of the Russian enterprise of horticulture production. International Transaction Journal of Engineering, Management \& Applied Sciences \$ Technologies, vol. 11 (6).

Turishcheva, T.B. and Shugurova, S.A. (2019) Actual Aspects of Formation of Accounting Policies for Taxation Purposes of Commercial Organizations. Proceedings of the 34th International Business Information Management Association Conference, IBIMA 2019: Education Excellence and Management of Innovations through Sustainable Economic Competitive Advantage Vision 2025, p.4893-4898.

Voronova, T. A., Golubtsova, E., V., Maksimov, D. A., Novikova, E. S. and Ponomareva, N., V. (2020) The Role of Taxation in the Competitiveness of Russian Education Following Globalization and Digitalization Processes in the World Economy. Turismo Estudos \& Práticas, vol. 2, p. 1-7

Voronova, T.A. and Novikova, E.S. (2019) Dynamics of Higher Education and Social and Economic Indicators Globally in Conditions of Digitalization Proceedings of the 34th International Business Information Management Association Conference, IBIMA 2019: Education Excellence and Management of Innovations through Sustainable Economic Competitive Advantage Vision 2025, p.1992-1999.

Zvereva, A.O., Golubtsova, E.V. and Tsilikova, M.S. (2020) The specifics of the use of tax instruments in the digital trade of the Russian Federation. In the Proceedings of the 7th International Conference on Education and Social Sciences (INTCESS), p. 44-50. 